\title{
Review
}

\section{Review of thermal imaging systems in composite defect detection}

\section{Jorge Aldave a,* , P. Venegas Bosom ${ }^{\text {a }}$, L. Vega González ${ }^{\text {a }}$, I. López de Santiago ${ }^{\text {a }}$, B. Vollheim ${ }^{\text {b,* }}$, L. Krausz ${ }^{\text {b, } 1}$, M. Georges ${ }^{c}$}

a Centro de Tecnologías Aeronáuticas (CTA), C/Juan de la Cierva 1, Parque Tecnológico de Álava, 01510 Vitoria-Gasteiz, Spain
${ }^{\mathrm{b}}$ InfraTec GmbH, Gostritzer Strasse 61-63, 01217 Dresden, Germany

${ }^{\mathrm{c}}$ Centre Spatial de Liège, Université de Liège, Liege Science Park, B-4031 Angleur, Belgium

\section{A R T I C L E I N F O}

\section{Article history:}

Received 26 September 2012

Available online 6 August 2013

\section{Keywords:}

Thermal camera

Infrared

Comparison

Composite Material

\begin{abstract}
A B S T R A C T
Thermal imaging technologies are widely used at present in many industrial areas, while being nowadays more and more employed in R\&D\&i activities. This article focuses on the comparison of the results obtained with commercially available non-experimental infrared (IR) cameras in the field of non-destructive defect detection. One of the cameras belongs to the FLIR SC5000 series, which is a Medium Wavelength Infrared (MWIR) camera, and the other two cameras are from the high-end ImageIR series manufactured by InfraTec GmbH: the ImageIR 8300 also belongs to the class of MWIR cameras and the ImageIR 8800 is a Long Wavelength Infrared (LWIR) camera.

The comparative study is carried out by means of inspecting three different calibrated and induced defect samples with these three cameras using similar excitation sources, so that the configuration and lay out of the tests are comparable with each other. Additionally, after every inspection, a mathematical post-processing is applied to the resulting raw thermal images in order to enhance the detection of defects present in the samples.
\end{abstract}

(c) 2013 Elsevier B.V. All rights reserved.

\section{Contents}

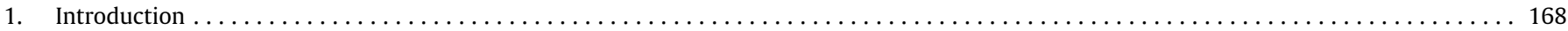

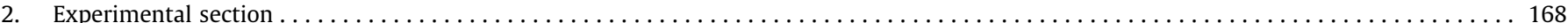

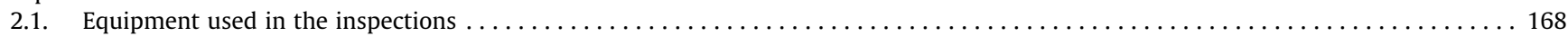

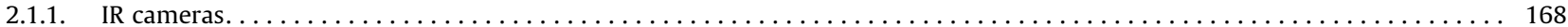

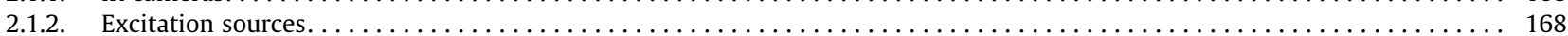

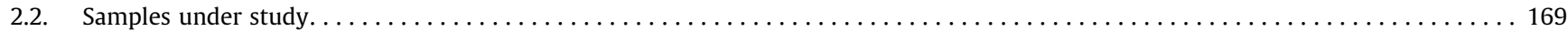

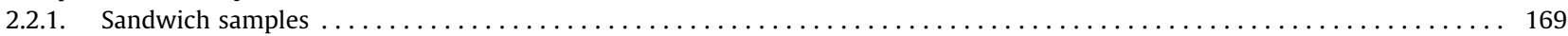

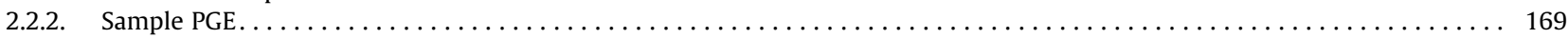

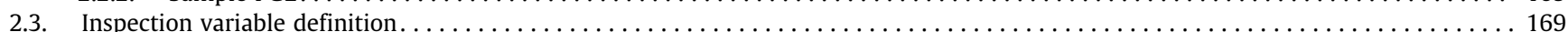

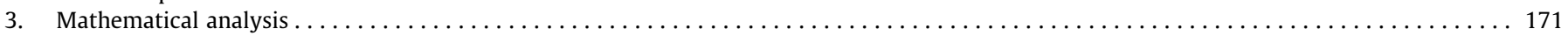

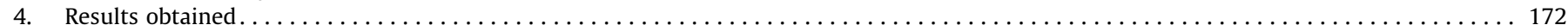

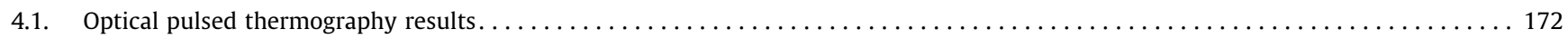

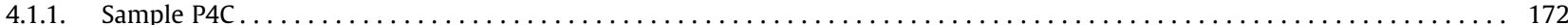

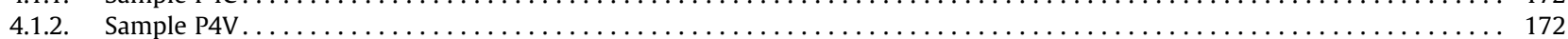

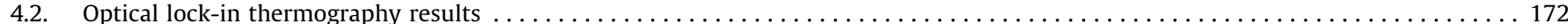

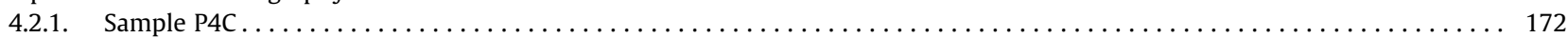

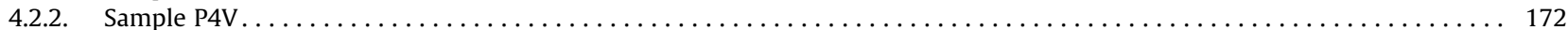

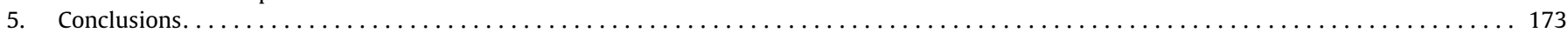

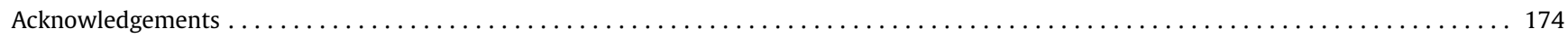

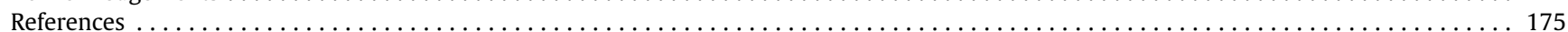

\footnotetext{
* Corresponding authors. Tel.: +34 945296924 (I.J. Aldave).

E-mail addresses: iagoba.jorge@ctaero.com (I. Jorge Aldave), B.Vollheim@infratec.de (B. Vollheim).

${ }^{1}$ This research was performed while L. Krausz was at InfraTec GmbH Laboratory, Gostritzer Strasse 61-63, 01217 Dresden, Germany.
} 


\section{Introduction}

The Infrared thermographic (IRT) technologies are used nowadays as a very fast NDT tool for examination of a wide range of materials, including composites [1]. IRT complements other NDT methods, mainly to ultrasonic testing (UT), especially where these latter have difficulties of detection, such as with superficial defects or inspections of glass fiber in the case of UT, or are directly unsuitable, for example if contactless inspections are required, which is an often situation. IRT is in principle applicable to every type of material [2], which makes this technique very flexible and versatile compared to other conventional NDT technologies. It is applicable in production as well as in maintenance works.

The inspection of a material or component by means of thermographic techniques consists of the measurement and interpretation of the temperature field over the component. The detecting device (infrared camera) receives different levels of infrared radiation from the surface of the sample, generating a map of its distribution, thus creating an image called thermogram.

The differences that may exist inside the structure of the object under evaluation create a different thermal conduction in the material, therefore affecting the heat flow. This means that different structural characteristics of the object to be inspected (either different internal structure or presence of defects), will make it cool down or warm up at different ratio [3]. As a result of this behavior, different thermal contrasts will be shown in the finally obtained thermogram.

The IRT methodology used for detection of defect is an active technique. This means that an additional energy must be supplied to the object to be inspected in order to establish the necessary heat flow which generates differences of temperature in the specimen. There are several excitation techniques to be used in active thermography, each one presents different advantages and is more appropriate depending on the type of defect or material to be analyzed. The use of optical, mechanical, or even inductive processes for stimulation is nowadays a usual way of creating thermal waves inside the materials without damaging.

The infrared cameras used in NDT applications can be classified according to the spectral range in Long Wavelength InfraRed (LWIR) and Medium Wavelength Infrared (MWIR), which depends directly on the kind of IR detector of the camera [11]. There exists several literature on the different types of sensors. In [5], Rogalski made a review of the infrared detector technologies, focused in the material systems for the infrared photon detection. Gavrilov et al. [6] made a comparison of near and mid infrared ban reflectography for art diagnosis, field in which the near-infrared is more used. A comparison to MWIR and LWIR of the near infrared thermography was made by Rotrou et al. [4], the paper is centered in the Silicon Plane Array of the near infrared camera and presents a calibration procedure for the cameras that are compared. However, a direct comparison of both technologies for active detection of defects in composite materials has not been realized yet, which is the main objective of this work.

\section{Experimental section}

Active infrared thermography consists of stimulating the surface of an object to be studied by means of a heat source in a controlled way. The dynamic response of the generated thermal wave along the surface is detected using an infrared camera which records the temperature evolution over time. The thermal sequence obtained from the camera can be processed afterwards to improve the results obtained.

Optical infrared thermography was the active technique chosen to perform the tests. Among optical stimulation methods, optical pulsed thermography (OPT) and optical lock-in thermography (OLT) were the selected techniques for the inspection of the selected items.

\subsection{Equipment used in the inspections}

For the development of the tests three infrared cameras were employed for this study, and also the necessary excitation devices were applied. Their main features are included in the following review.

\subsubsection{IR cameras}

Three thermographic cameras were used in the performed inspections as infrared detecting devices: An SC5000 model of CEDIP/FLIR Infrared Systems, which is a Medium Wavelength Infrared (MWIR) camera, and two IR cameras of the high-end ImageIR series by InfraTec GmbH: the ImageIR 8300 (MWIR) and ImageIR 8800 (LWIR). The characteristics of each of them are described in Table 1.

The use of cameras with characteristics like the mentioned ones offers higher levels of defect detection, since they have a higher sensitivity and faster thermal image acquisition process than other conventional models.

\subsubsection{Excitation sources}

For the OPT technique flash lamps and their corresponding generators have been used as heat sources, in order to excite the specimens by heat pulses (close to theoretical Dirac delta signal during three milliseconds). Each flash lamp is powered by two generators able to supply $3 \mathrm{~kJ}$ of energy each one. The lamps have a parabolic shape which projects the light directly towards the surface to be heated and thereby reducing power losses.

For the OLT tests, halogen lamps are employed. With halogen lamps the emitted radiation can be modulated in both amplitude and frequency using an appropriate control hardware and software.

For OLT and lock-in testing, InfraTec uses a specifically developed measuring site. The main advantages of this site, compared to commonly used OLT halogen lamp set-ups, are the insensitivity to environmental radiation sources (reflections), due to the small cavity of the site where the tests are conducted with no change in environmental condition, and a better homogeneity of the energy provided along the surface of the inspected object, obtained

Table 1

Characteristics of the infrared cameras to be compared.

\begin{tabular}{|c|c|c|c|}
\hline Characteristic & FLIR SC5000 & ImageIR 8300 & ImageIR 8800 \\
\hline Infrared spectral range & $3.6-5.1 \mu \mathrm{m}$ & $2.0-5.5 \mu \mathrm{m}$ & $8.0-11.0 \mu \mathrm{m}^{\mathrm{a}}$ \\
\hline $\begin{array}{l}\text { Measuring temperature } \\
\text { range }\end{array}$ & $\begin{array}{l}-20^{\circ} \mathrm{C} \text { to } \\
+55^{\circ} \mathrm{C}\end{array}$ & $\begin{array}{l}-20^{\circ} \mathrm{C} \text { to } \\
+55^{\circ} \mathrm{C}\end{array}$ & $\begin{array}{l}-20^{\circ} \mathrm{C} \text { to } \\
+55^{\circ} \mathrm{C}\end{array}$ \\
\hline Detector array & $\begin{array}{l}\text { Indium } \\
\text { antimonide }\end{array}$ & $\begin{array}{l}\text { Indium } \\
\text { antimonide }\end{array}$ & $\begin{array}{l}\text { Mercury } \\
\text { cadmium } \\
\text { Telluride } \\
\text { (MDT) }\end{array}$ \\
\hline Type of cooling & $\begin{array}{l}\text { Integrated } \\
\text { stirling } \\
\text { cooler }\end{array}$ & $\begin{array}{l}\text { Integrated } \\
\text { stirling } \\
\text { cooler }\end{array}$ & $\begin{array}{l}\text { Integrated } \\
\text { stirling } \\
\text { cooler }\end{array}$ \\
\hline Frame rate (full frame) & $5-380 \mathrm{~Hz}$ & $1-100 \mathrm{~Hz}$ & $1-100 \mathrm{~Hz}$ \\
\hline Thermal resolution & $\begin{array}{l}\text { Less than } \\
30 \mathrm{mK}\end{array}$ & $\begin{array}{l}\text { Less than } \\
20 \mathrm{mK}\end{array}$ & $35 \mathrm{mK}$ \\
\hline Number of pixels & $320 \times 256$ & $\begin{array}{l}640 \times 512 \\
\text { pixels }\end{array}$ & $\begin{array}{l}640 \times 512 \\
\text { pixels }\end{array}$ \\
\hline Integration time & $10-20,000 \mu \mathrm{s}$ & $1-20,000 \mu \mathrm{s}$ & $1-20,000 \mu \mathrm{s}$ \\
\hline
\end{tabular}

a The used camera is equipped with a special detector which is responsive up to $11 \mu \mathrm{m}$ wavelength, as it should not only be suited for thermography, but also for non-destructive testing by holography and shearography techniques investigations applying a $\mathrm{CO}_{2}$ laser at $10.6 \mu \mathrm{m}$ wavelength. The ImageIR 8800 series is usually available with spectral ranges of (8-9.4) $\mu \mathrm{m}$ or (8-10.2) $\mu \mathrm{m}$, respectively. 
by arranging 4 halogen lamps in a specific position to create a broad and homogeneous excitation area.

\subsection{Samples under study}

Three different composite samples, described hereafter, have been studied.

\subsubsection{Sandwich samples}

Samples P4V and P4C are both manufactured in composite sandwich structure, with composite skins and honeycomb core. The skin layers of the sample P4V are made of glass fiber reinforced polymer (GFRP), meanwhile the layers of the sample P4C are made of carbon fiber reinforced polymer (CFRP) (see Figs. 1-5).

The dimensions of the inspection surface are $360 \mathrm{~mm} \times$ $300 \mathrm{~mm}$ (see Fig. 6). Additionally, this surface was manufactured in a step configuration, so the area of this surface which contains the largest number of layers has a maximum of 12 layers, followed by areas of 9, 6 and 3 layers progressively. On the other hand, the lower skin of each sample is uniform and contains 3 layers with no induced defects (see Fig. 7).

The induced defects present in both samples are node separation in core and cracked core defects, as well as disbonding areas, according to the following Table 2 .

\subsubsection{Sample PGE}

The sample PGE is a big thickness sample, up to $15 \mathrm{~mm}$, intentionally designed to test the limits of detection in thickness of the IRT technology (see Table 3).

These layers are also distributed in a step configuration over the defects. As a result of this, there are 4 sections in the PGE sample, with different number of plies, approximately $0.41 \mathrm{~mm}$ thick each one. In the thinnest section the defects are located under $3 \mathrm{~mm}$, $6 \mathrm{~mm}$ in the next thicker section, $8 \mathrm{~mm}$ in the next thicker section, and $10 \mathrm{~mm}$ in the thickest one.

The induced defects are Polytetrafluoroethylene (PTFE), film and metal inserts, and the sample is monolithic, thus without core in the middle of the structure. PTFE and film are materials usually used in the production of composite materials. The first one is used as a tool during the stacking process, and the second one is part of the raw material which shall be completely eliminated before sample shaping. The metal inserts are cutter leaf segments, since it is very common in composite production that the cutter used is broken, and these segments get trapped in the final assembly between two layers.

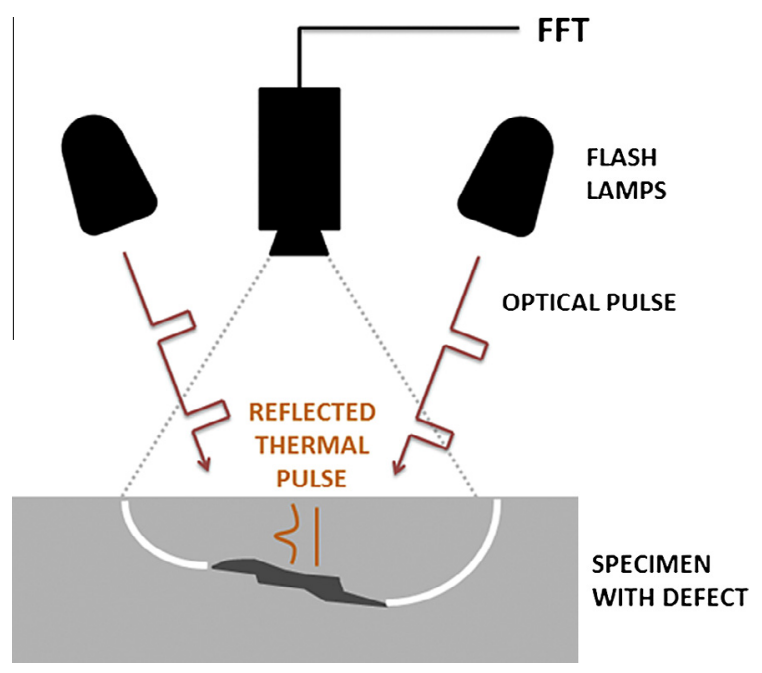

Fig. 2. Optical pulsed thermography test.

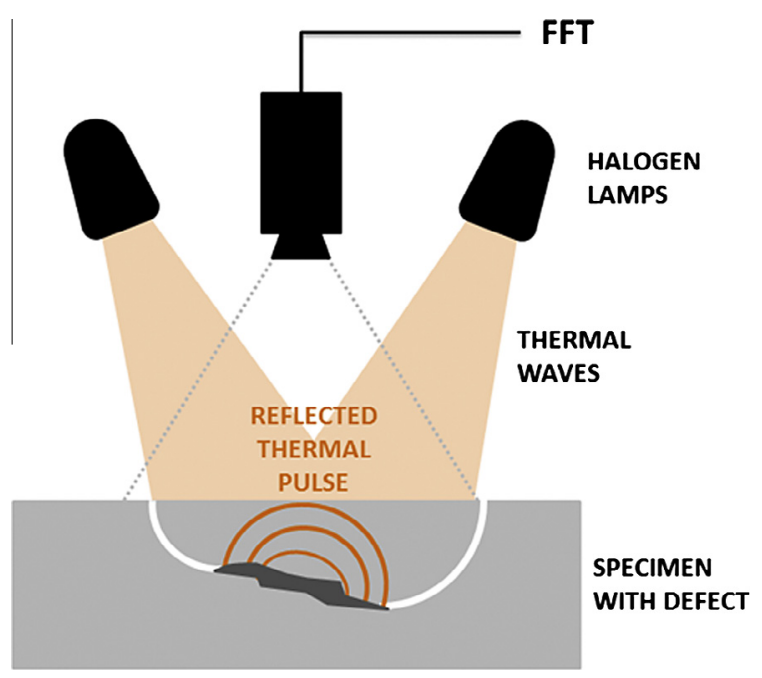

Fig. 3. Optical lock-in thermography test.

\subsection{Inspection variable definition}

OPT technique consists in warming up the samples by a massive and sudden shot of energetic light in a short period of time and observing the evolution of the surface temperature of the sample

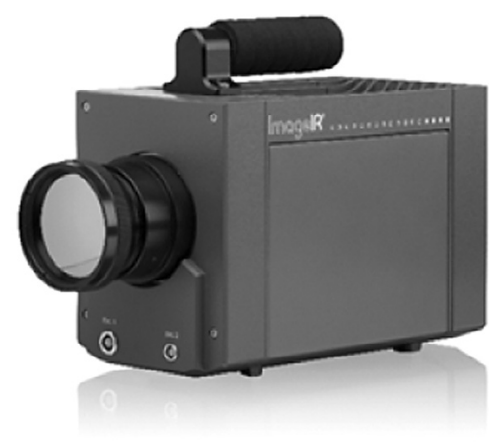

(b)

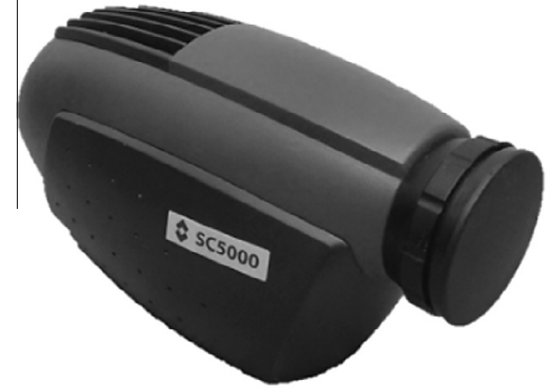

(a)

Fig. 1. The infrared thermographic cameras used: (a) Silver SC5000 and (b) ImageIR series by InfraTec. 


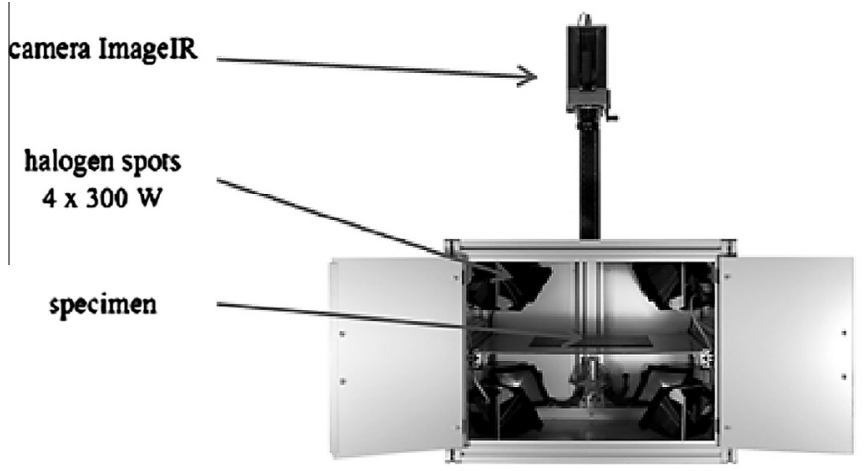

(a)

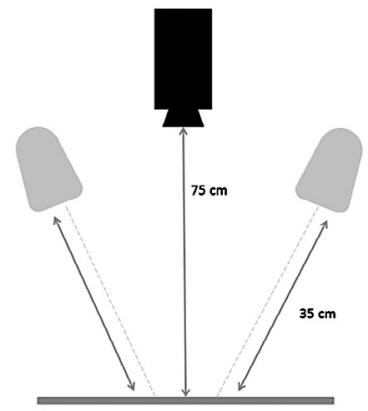

(b)

Fig. 4. Measuring chamber for excitation by halogen lamps.

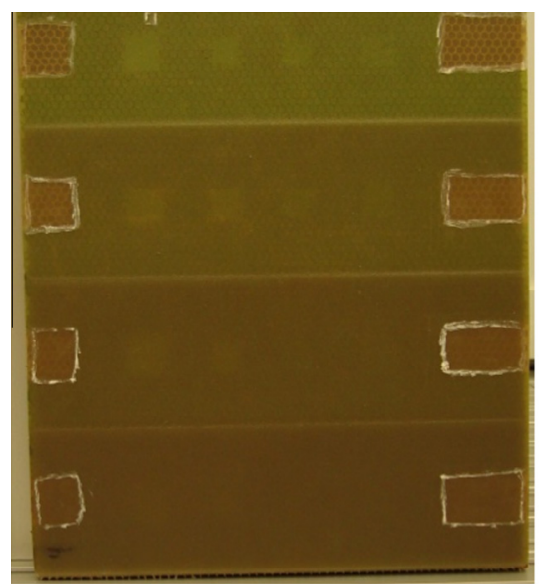

(a)

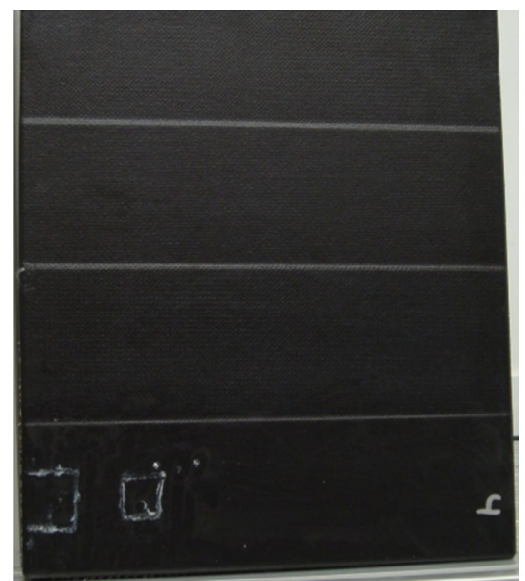

(b)

Fig. 5. Inspected sandwich samples. Vacuum bag side. (a) Sample P4V and (b) Sample P4C.

just after the excitation. This allows identifying various defects in the specimen.

The parameters selected to carry out the OPT tests were $2500 \mu \mathrm{s}$ of integration time and a frame rate of $50 \mathrm{~Hz}$. For all cameras, the distances taken between sample, camera and lamps are the following ones:

- Lamps-Samples: $35 \mathrm{~cm}$.

- Camera-Samples: $75 \mathrm{~cm}$.

Previous experiences of the authors show that these distances give good results when testing with OPT.

In OPT tests, a background subtraction process is often applied, which implies to remove to the entire recorded sequence a reference image taken from the same sequence. Usually this reference image taken from the sequence is the thermogram just after the flash. The main advantage obtained with this procedure is the elimination of great quantity of non-desired energy reflections. This is a way to obtain clear results without false defect detection or even enhance some underlying defects, hidden by the reflections.

Finally, the result obtained with OPT technique is a sequence of IR images, in which each pixel corresponds to a specific temperature at any precise instant [10]. These images obtained in the time domain, can be represented in the frequency domain as "amplitude image" and "phase image" (phase images are less affected by heterogeneities thus resulting in a higher stability in front of perturbations than the raw thermograms). This is exactly what lock-in thermography tries to achieve in a direct way.

Lock-in thermography uses frequency and amplitude modulated stimulation, while the infrared camera takes images in synchronization with the excitation source. Then OLT technique employs a numerical algorithm to directly obtain the amplitude and phase component values of the temperature time history but represented in the frequency domain. This results in a reduction of the quantity of data as well as in a higher quality of the IR images.

$A\left(x_{1}\right)=\sqrt{\left[S_{1}\left(x_{1}\right)-S_{3}\left(x_{1}\right)\right]^{2}-\left[S_{2}\left(x_{1}\right)-S_{4}\left(x_{1}\right)\right]^{2}}$

$\phi\left(x_{1}\right)=\operatorname{arctg}\left[\frac{S_{1}\left(x_{1}\right)-S_{3}\left(x_{1}\right)}{S_{2}\left(x_{1}\right)-S_{4}\left(x_{1}\right)}\right]$

where $x_{1}$ is the selected pixel and $S_{1}, S_{2}, S_{3}$ and $S_{4}$ are the values measured by the IR camera, taken equally spaced in time.

Although OLT is more sensitive to defects than OPT, it can be however much slower due to the fact that for each depth to be inspected inside the sample, a different test with a certain stimulation frequency (and also acquisition frequency) during several cycles has to be conducted to obtain a complete acquisition.

The values selected for the OLT tests with the Flir and InfraTec cameras are shown in the following Tables 4 and 5: 

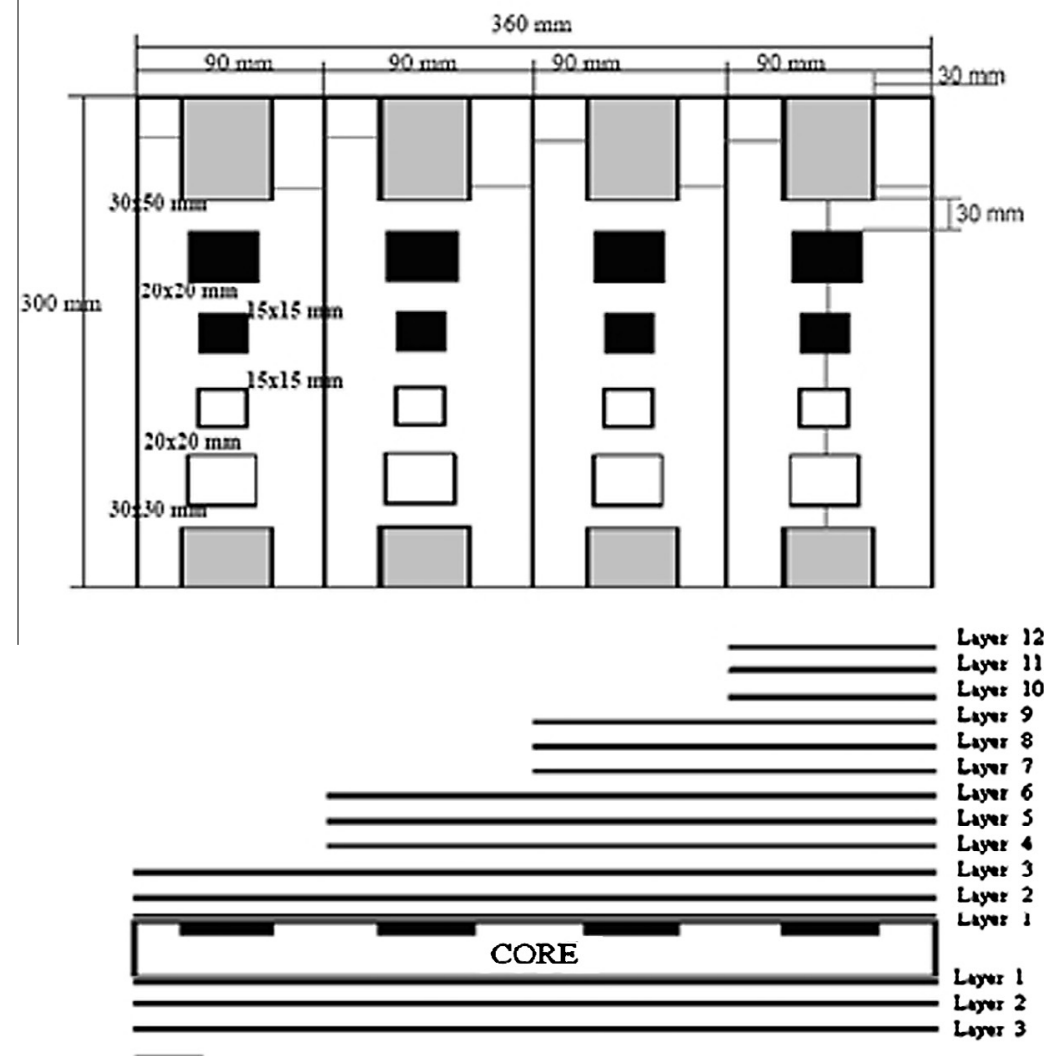

Now mpration in eon

Crockoden

Fig. 6. Schematic view of sample P4V and P4C including the four section definition.

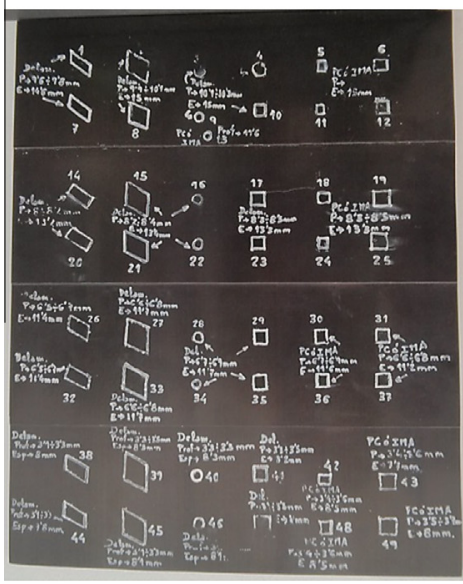

(a)

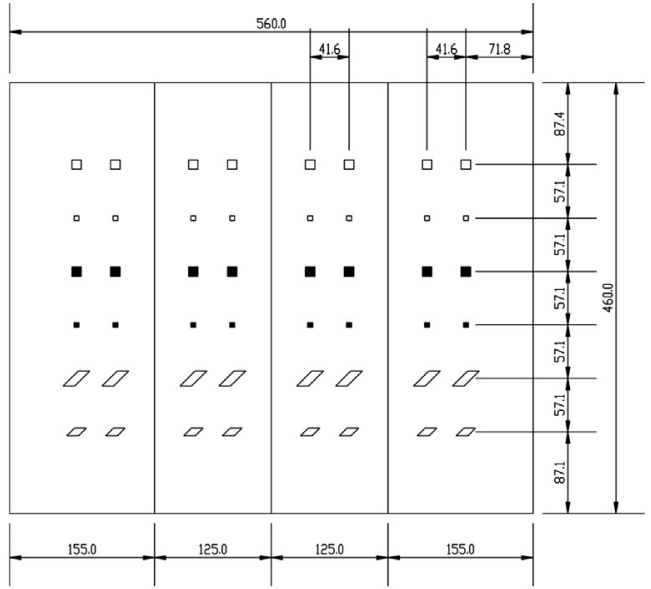

(b)

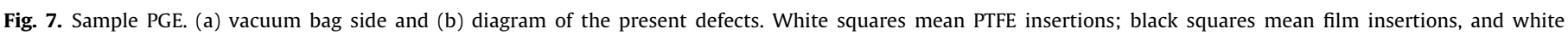
parallelepiped mean cutter metal insertions.

As an example, a resulting phase image of the sample P4V taken with the camera ImageIR 8300 and OLT technique is shown in Fig. 8. The contrast between defects and background could be enhanced by adjusting the scale of the thermal image (see Figs. 9-12).

\section{Mathematical analysis}

The OPT sequences were processed applying the algorithm of Pulse-Phase Thermography (PPT) [3]. The sequences undergo a 
Table 2

Present defects in samples P4V and P4C (mm).

\begin{tabular}{|c|c|c|c|c|}
\hline Defect/size (mm) & $15 \times 15^{\mathrm{a}}$ & $20 \times 20^{\mathrm{a}}$ & $30 \times 30 \mathrm{~mm}^{\mathrm{a}}$ & $30 \times 50^{a}$ \\
\hline Node separation & 4 units & & 4 units & \\
\hline Cracked core & 4 units & & 4 units & \\
\hline Disbonding & & & 4 units & 4 units \\
\hline
\end{tabular}

a Each defect made of same size is located in different thickness area of the sample.

Table 3

Present defects in sample PGE $(\mathrm{mm})$.

\begin{tabular}{lllll}
\hline Defect/size $(\mathrm{mm})$ & $10 \times 10^{\mathrm{a}}$ & $5 \times 5^{\mathrm{a}}$ & Cutter segment $^{\mathrm{a}}$ & Half cutter segment $^{\mathrm{a}}$ \\
\hline PTFE & 8 units & 8 units & \\
Film & 8 units & 8 units & \\
Metal & & & 8 units & 8 units \\
\hline
\end{tabular}

a Two equal inserts are located in each section of the sample.

Table 4

OLT test variable definition for Flir camera.

\begin{tabular}{llllll}
\hline $\begin{array}{l}\text { Lock-in } \\
\text { frequency } \\
(\mathrm{Hz})\end{array}$ & $\begin{array}{l}\text { Amplitude } \\
(\%)\end{array}$ & $\begin{array}{l}\text { Acquisition } \\
\text { periods }\end{array}$ & $\begin{array}{l}\text { Lock-in } \\
\text { frequency } \\
(\mathrm{Hz})\end{array}$ & $\begin{array}{l}\text { Amplitude } \\
(\%)\end{array}$ & $\begin{array}{l}\text { Acquisition } \\
\text { periods }\end{array}$ \\
\hline 0.01 & 40 & 1 & 0.05 & 40 & 2 \\
0.01 & 40 & 2 & 0.05 & 40 & 4 \\
0.01 & 40 & 3 & 0.05 & 40 & 6 \\
0.01 & 60 & 1 & 0.05 & 60 & 2 \\
0.01 & 60 & 2 & 0.05 & 60 & 4 \\
0.01 & 60 & 3 & 0.05 & 60 & 6 \\
0.01 & 80 & 1 & 0.05 & 80 & 2 \\
0.1 & 40 & 10 & 0.5 & 40 & 20 \\
0.1 & 40 & 15 & 0.5 & 40 & 30 \\
0.1 & 60 & 10 & 0.5 & 60 & 20 \\
0.1 & 60 & 10 & 0.5 & 60 & 30 \\
0.1 & 80 & 10 & 0.5 & 80 & 20 \\
\hline
\end{tabular}

Table 5

OLT test variable definition for InfraTec camera.

\begin{tabular}{llllll}
\hline $\begin{array}{l}\text { Lock-in } \\
\text { frequency } \\
(\mathrm{Hz})\end{array}$ & $\begin{array}{l}\text { Amplitude } \\
(\%)\end{array}$ & $\begin{array}{l}\text { Acquisition } \\
\text { periods }\end{array}$ & $\begin{array}{l}\text { Lock-in } \\
\text { frequency } \\
(\mathrm{Hz})\end{array}$ & $\begin{array}{l}\text { Amplitude } \\
(\%)\end{array}$ & $\begin{array}{l}\text { Acquisition } \\
\text { periods }\end{array}$ \\
\hline 0.005 & 90 & 1 & 0.03 & 90 & 2 \\
0.005 & 90 & 2 & 0.03 & 90 & 4 \\
0.005 & 90 & 3 & 0.03 & 90 & 6 \\
0.01 & 90 & 1 & 0.05 & 90 & 2 \\
0.01 & 90 & 2 & 0.05 & 90 & 4 \\
0.01 & 90 & 3 & 0.05 & 90 & 6 \\
0.02 & 90 & 1 & 0.1 & 90 & 10 \\
0.02 & 90 & 2 & 0.1 & 90 & 20 \\
0.02 & 90 & 3 & 0.1 & 90 & 30 \\
\hline
\end{tabular}

pixel-wise Fourier Transformation for selected frequencies which results in amplitude and phase images, similarly to the data processing of lock-in thermography [2].

In order to calculate the phase of the thermographic data, the temperature time history of each pixel during the test is transformed into the frequency domain using the Discrete Fourier Transform (DFT). The DFT is applied on the temperature time history of each pixel using (1), where $i$ is the imaginary number, $n$ is the frequency increment, $T(k)$ designates the temperature and $R e_{n}$ and $\mathrm{Im}_{n}$ are the real and imaginary partes of the DFT [9].

$F_{n}=\sum_{k=1}^{N-1} T(k) e^{\frac{2 \pi i k n}{2 N}}=R e_{n}+\operatorname{Im}_{n}$
The phase is finally computed using (2).

$\emptyset_{n}=\operatorname{atan}\left(\frac{I m_{n}}{R e_{n}}\right)$

\section{Results obtained}

Here are shown the results obtained in the inspections carried out using the three cameras to be compared. The quality of detection in the results has been classified following this scale: 3 if the defect is clearly visible, 2 if it is visible, 1 if it is barely visible and 0 if it is not visible.

\subsection{Optical pulsed thermography results}

In the following graphics, the results obtained with each of the MWIR cameras are shown.

\subsubsection{Sample P4C}

The results obtained by the camera ImageIR 8300 are clearly better than those obtained by the FLIR model. The level of detection of the ImageIR 8300 camera is higher, and moreover, the camera ImageIR was able to detect the node separation in both of the available sizes. It is interesting to note that the level of detection of the cracked core is low, just barely visible.

\subsubsection{Sample P4V}

Qualitatively, the results obtained with the ImageIR 8300 are better for the detected defects, despite the fact that there was no detection for the cracked core, defect that was positively detected with the FLIR camera, but only barely and for the most surface defect. The depth reached by the camera ImageIR is higher, and additionally, the FLIR camera is not able to detect the deepest node separation defects.

Finally, it deserves to be pointed that the quality of detections obtained with OPT technique in the inspection of the GFRP sample, $\mathrm{P} 4 \mathrm{~V}$, was higher than that obtained in the CFRP sample, with highest levels in most cases. However, the number of detections was lower than in the inspection of the CFRP sample, P4C, which offers better results considering that the cracked core defects present in the sample were detected, contrary to the results obtained in the GFRP sample.

\subsection{Optical lock-in thermography results}

In the following graphics, the results obtained with the three cameras under study are shown.

\subsubsection{Sample $P 4 C$}

With OLT excitation, the results are similar to those obtained with OPT technique. The results with the FLIR camera are worse than the results with the ImageIR series. The FLIR camera was not able to detect the smallest node separation defect; however, ImageIR cameras detected this defect clearly for all the depths and also detected the deeper cracked cores.

\subsubsection{Sample P4V}

In this case, the results are similar to the CFRP sample with respect to the type of defects detected. Nevertheless, the levels of detection are quite different, and the lowest ones are obtained with the LWIR camera, this is the ImageIR 8800. In this case, unlike in the sample P4C, the shallowest cracked core defects were detected only by the FLIR camera.

For the sample PGE, the ImageIR cameras did not obtain any indication. In the case of the tests carried out with the FLIR camera, 


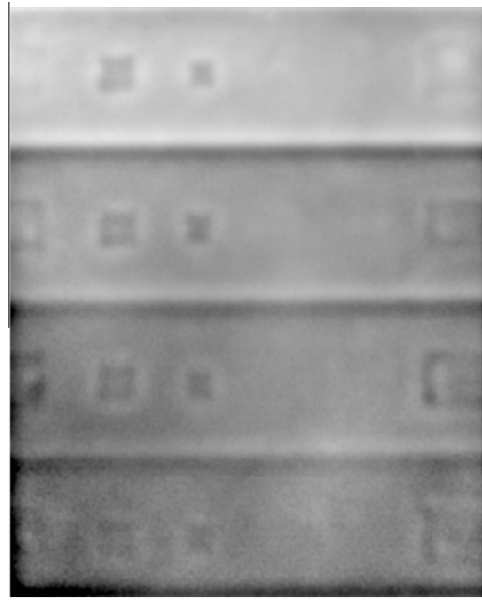

(a)

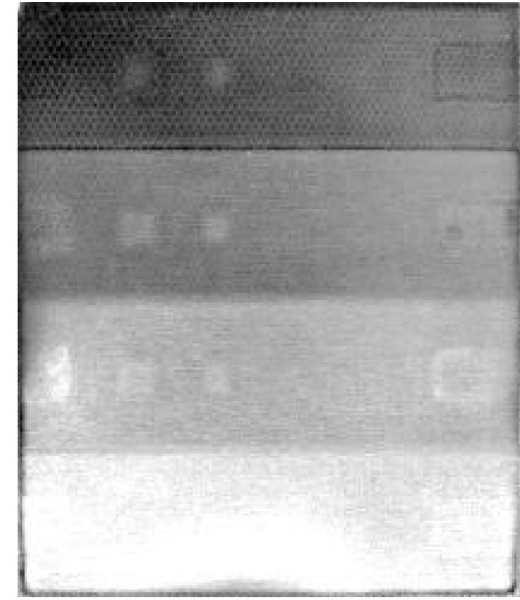

(b)

Fig. 8. Phase image taken at sample P4V: (a) with ImageIR 8300 and OLT technique and (b) with FLIR camera and OLT technique.
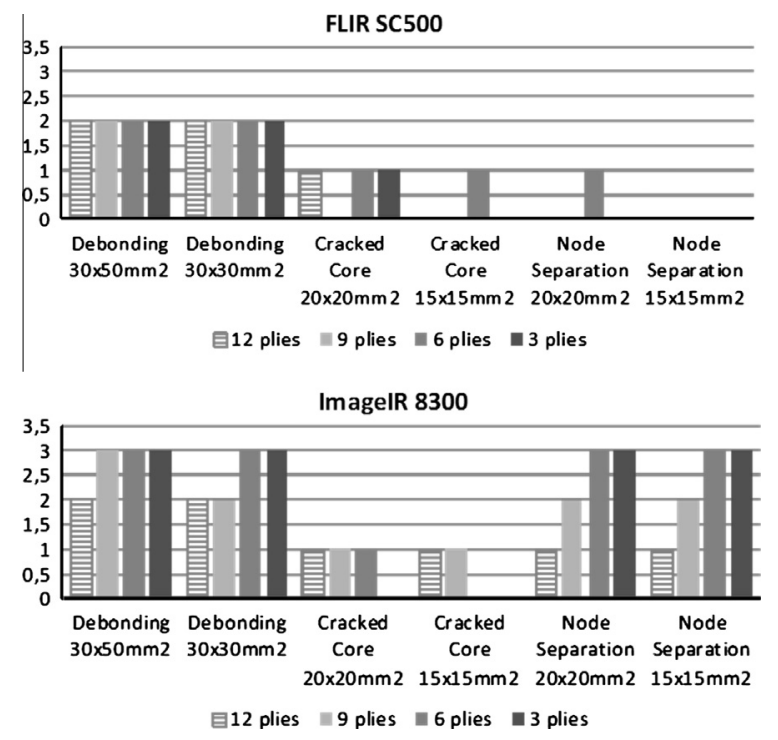

Fig. 9. Results obtained for the P4C sample with the MWIR cameras using OPT technique.

using the OBT technique [9], some indications appeared, but they were not clear and were not considered in this study due to the lack of comparability with the other IR techniques (see Fig. 13).

\section{Conclusions}

The disbonding and node separation defects in the samples P4C and P4V were detected with both excitation techniques and all IR cameras. The sample P4V (glass fiber composite) obtained higher levels of detection for these defects in comparison to P4C (carbon fiber composite), especially in the thicker sections of the sample. The excitation by flash lamps provided slightly better results for the thinner sections of sample P4C (3, 6 layers). The defect detectability in the thicker sections of P4C (9, 12 layers) was improved with the use of modulated halogen lamps. Some defects are better visible after adjusting the scale of the thermal image to the sample thickness.
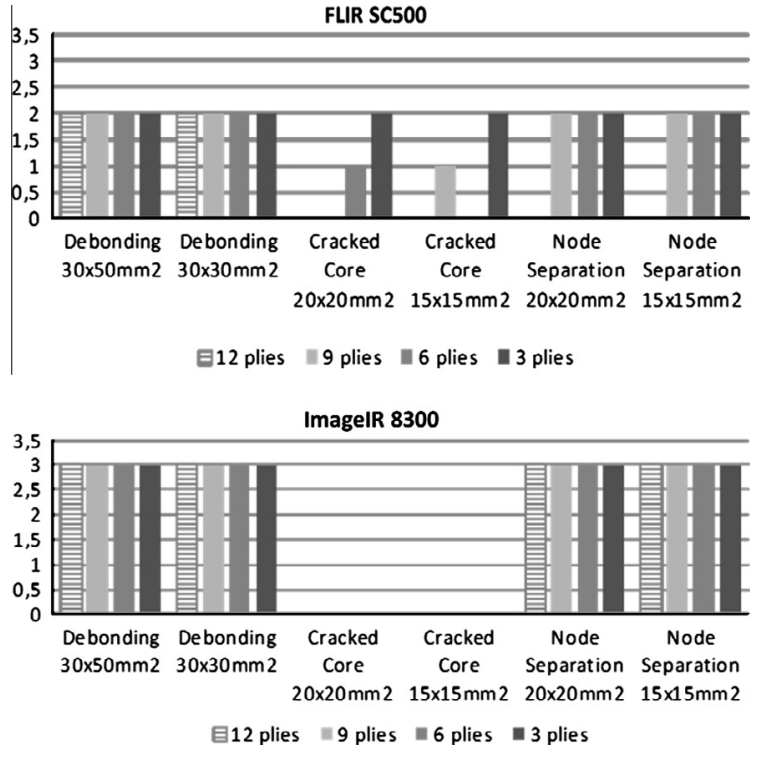

Fig. 10. Results obtained for the P4V sample with the MWIR cameras using OPT technique.

The cracked cores were only barely visible in the thicker sections of sample P4C (not in P4V) and only in the tests with both ImageIR cameras. The defects in the PGE sample could not be clearly detected.

The cameras ImageIR 8300 and 8800 achieved better contrasts for node separations and cracked cores (especially under 6, 9, 12 layers) as well as disbonding defects in the thicker sections of the sample P4C. They offered generally a higher geometrical resolution of the images due to their 4-fold pixel number.

The camera ImageIR 8800 (LWIR) provided comparable results to ImageIR 8300 (MWIR) for the sample P4C. The contrasts between defect and sound areas of the P4V sample are however lower for the LWIR camera. The different spectral emissivity of the P4V surface could be one possible reason.

According to the types and characteristics of the technologies analyzed in this work, the relatively worse results achieved with the LWIR camera could be explained by different reasons. Despite the higher irradiance (incident power) in that spectral range for the testing temperatures the contrast between differential and 

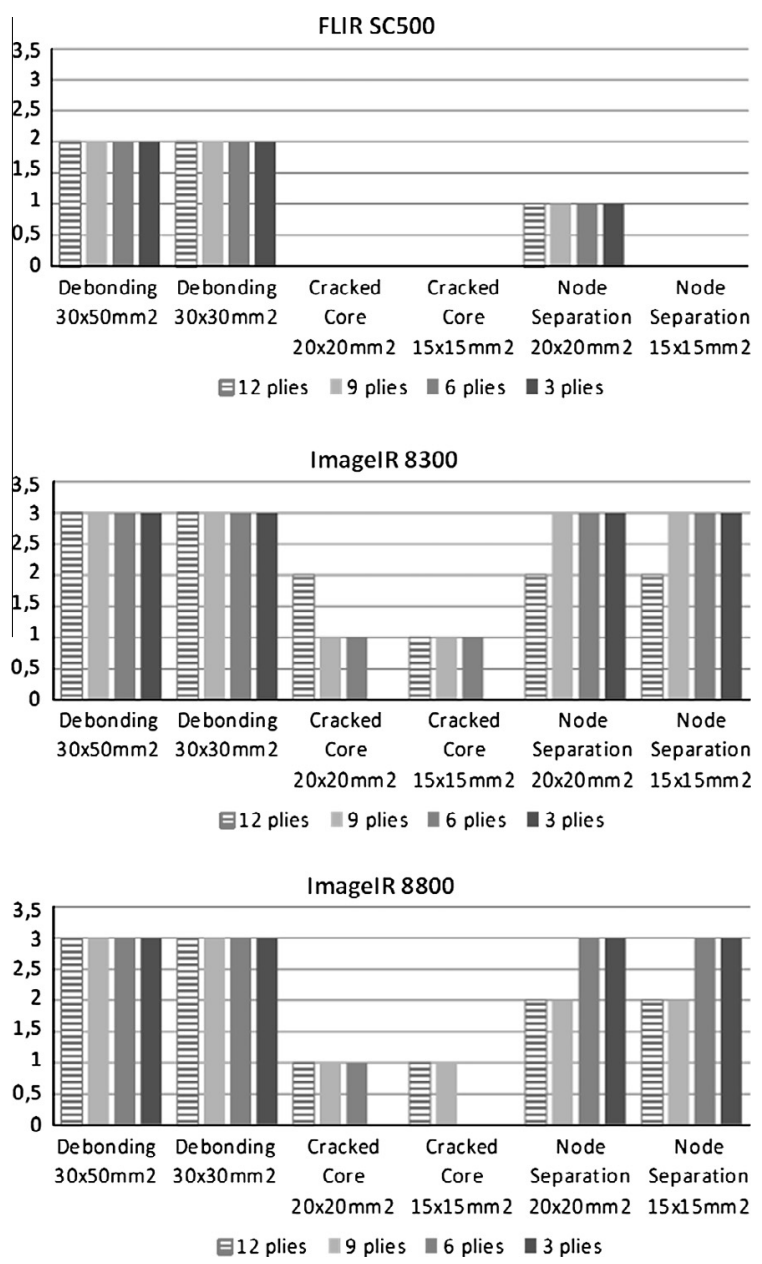

Fig. 11. Results obtained for the $\mathrm{P} 4 \mathrm{C}$ sample with the three cameras using OLT technique.

background radiation is higher in the MWIR. Moreover, reflections at the surfaces under observation and a higher Remaining Fixed Pattern Noise of the MCT detector array induced by the much more difficult LWIR photodiode technology can impede the detection of small differential signals. This behavior is also related to the high technological advances experienced by the MWIR technology, which makes it most appropriate for NDT tasks. Among the two MWIR technologies analyzed in this work, it is clearly stated that the camera with higher spatial resolution allows a higher level of detection.

Another important conclusion detected in the analysis of the results is the great capacity of improvement that the data processing techniques offer. In this work only a very simple processing methodology was applied to all the tests. Nevertheless, there exist many other methodologies which may offer even better results depending on the type of excitation technique applied or even the type of material under study or the type of present defects.

Finally, the influence of the measuring site developed by InfraTec, is considered not to improve the level of detection significantly in comparison to the tests conducted by CTA, since both of them were laboratory conditioned inspections. Probably, this measuring site would provide much better comparative results for in situ inspections.

In conclusion, it may be stated that active IRT technology is an effective, fast and non contact NDT tool for detection of superficial and sub-superficial defects in composite materials. It is expected in the near future that new technological advances, together with
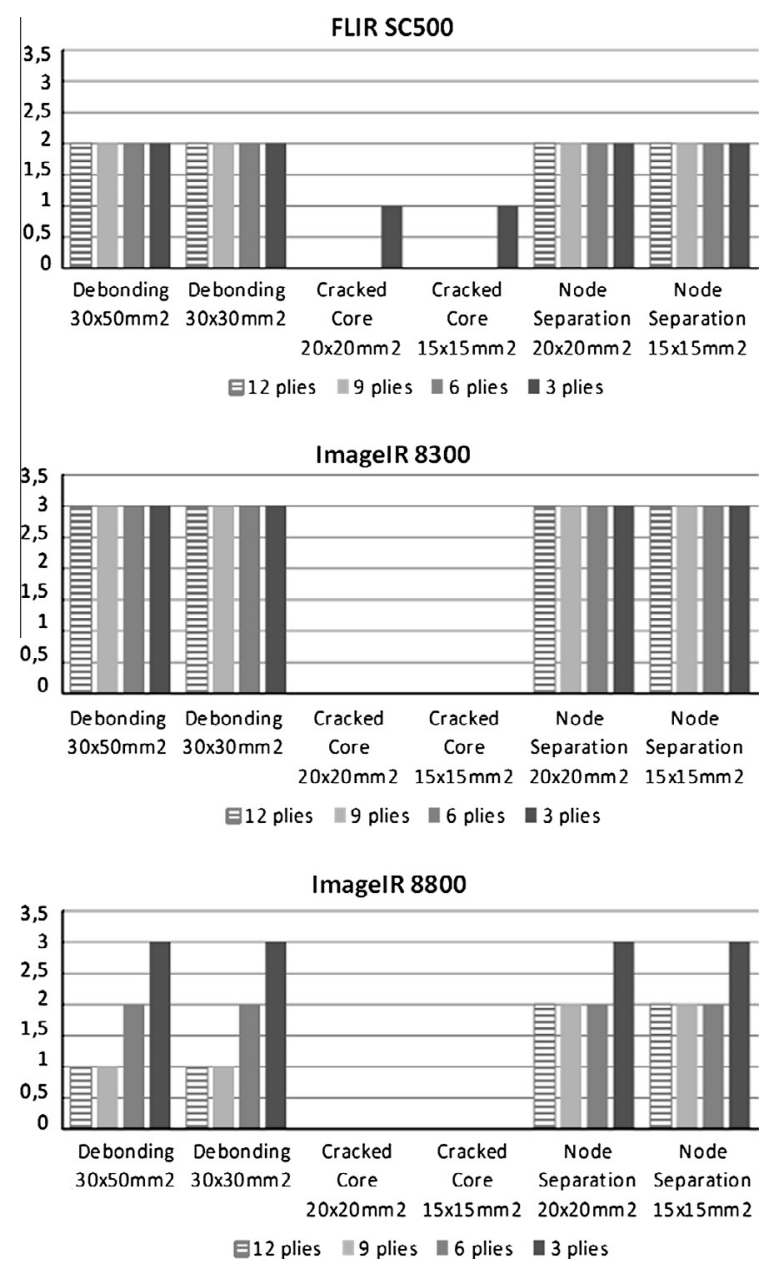

Fig. 12. Results obtained for the P4V sample with the three cameras using OLT technique.

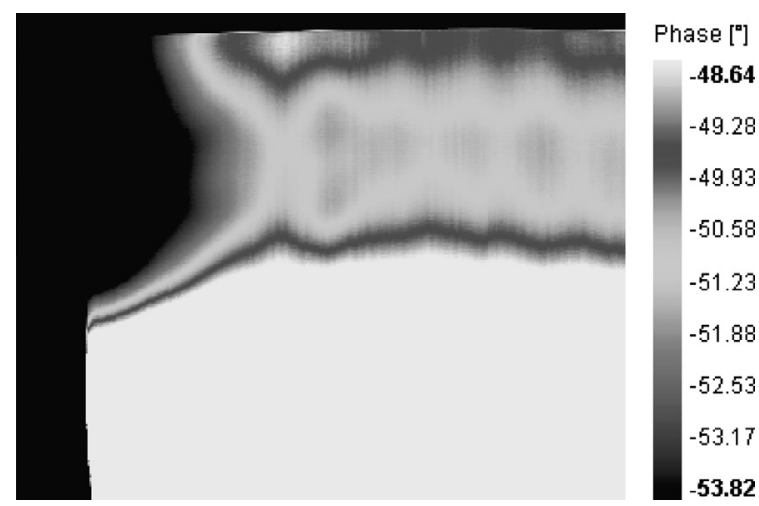

Fig. 13. Thermogram with indications in the sample PGE.

mathematical post processing methodologies, may improve the capacity of in depth detection of defects.

\section{Acknowledgements}

The investigations leading to this publication have been supported by the European Commission (EU project FANTOM: Full Field Advanced Non-Destructive Technique for Online Thermo-Mechanical Measurement on Aeronautical Structures, 
Grant Agreement No.: ACP7-GA-2008-213457). All the authors would like to thank the European Commission and all the partners of the project for their support.

\section{References}

[1] M. Georges, C. Thizy, J.-F. Vandenrijt, I. Alexeenko, G. Pedrini, W. Osten, I.J. Aldave, I. Lopez, I. Saez de Ocariz, B. Vollheim, G. Dammass, M. Krausz, FANTOM Project: Electronic Speckle Pattern Interferometry at Thermal Infrared Wavelengths, a New Technique for Combining Temperature and Displacement Measurements, 1st European Aeronautics Science Network (EASN) Workshop, EADS, October 7-8, Suresnes (France), 2010.

[2] T. D'Orazio, M. Leo, C. Guaragnella, A. Distante, Analysis of image sequences for defect detection in composite materials. In Advanced Concepts for Intelligent Vision Systems, Springer Berlin Heidelberg, January 2007, pp. 855-864.

[3] X. Maldague, Theory and practice of infrared technology for nondestructive testing, 2001.
[4] Y. Rotrou, T. Sentenac, Y. Le Maoult, P. Magnan, J. Farré, Near infrared thermography with silicon FPA-comparison to MWIR and LWIR thermography, Quantitative InfraRed Thermography Journal 3 (1) (2006) $93-$ 115.

[5] A. Rogalski, Recent progress in infrared detector technologies, Infrared Physics and Technology 54 (3) (2011) 136-154.

[6] D. Gavrilov, C. Kais, E. Maeva, R.G. Maev, A comparison of near- and midinfrared band reflectography in the diagnostics of artwork, in: Quantitative Infrared Thermography conference (QIRT), 2010.

[9] R. Usamentiaga, P. Venegas, J. Guerediaga, L. Vega, I. López, Non-destructive inspection of drilled holes in reinforced honeycomb sandwich panels using active thermography, Infrared Physics and Technology 55 (6) (2012) 491-498.

[10] C. Ibarra-Castanedo, D. González, M. Klein, M. Pilla, S. Vallerand, X. Maldague, Infrared image processing and data analysis, Infrared Physics and Technology $46(1-2)(2004) 75-83$.

[11] S. Laguela, H. Gonzalez-Jorge, J. Armesto, P. Arias, Calibration and verification of thermographic cameras for geometric measurements, Infrared Physics and Technology. 